\title{
Synthesis of a Core Arabinomannan
}

\section{Oligosaccharide of Mycobacterium Tuberculosis}

\author{
Alexandra Hölemann, Bridget L. Stocker and Peter H. Seeberger*
}

\section{Supporting Information - Part III}

\section{Mannan Hexasaccharide}

\section{Table of Contents}

${ }^{1} \mathrm{H}$ NMR and ${ }^{13} \mathrm{C}$ NMR spectra of compound 23 S2-S3

${ }^{1} \mathrm{H}$ NMR and ${ }^{13} \mathrm{C}$ NMR spectra of compound 25 S4-S5

${ }^{1} \mathrm{H}$ NMR and ${ }^{13} \mathrm{C}$ NMR spectra of compound 26 S6-S7

${ }^{1} \mathrm{H}$ NMR and ${ }^{13} \mathrm{C}$ NMR spectra of compound 28 S8-S9

${ }^{1} \mathrm{H}$ NMR and ${ }^{13} \mathrm{C}$ NMR spectra of compound 29

${ }^{1} \mathrm{H}$ NMR and ${ }^{13} \mathrm{C}$ NMR spectra of compound 30

${ }^{1} \mathrm{H}$ NMR and ${ }^{13} \mathrm{C}$ NMR spectra of compound 2

${ }^{1} \mathrm{H}$ NMR and ${ }^{13} \mathrm{C}$ NMR spectra of compound 3 

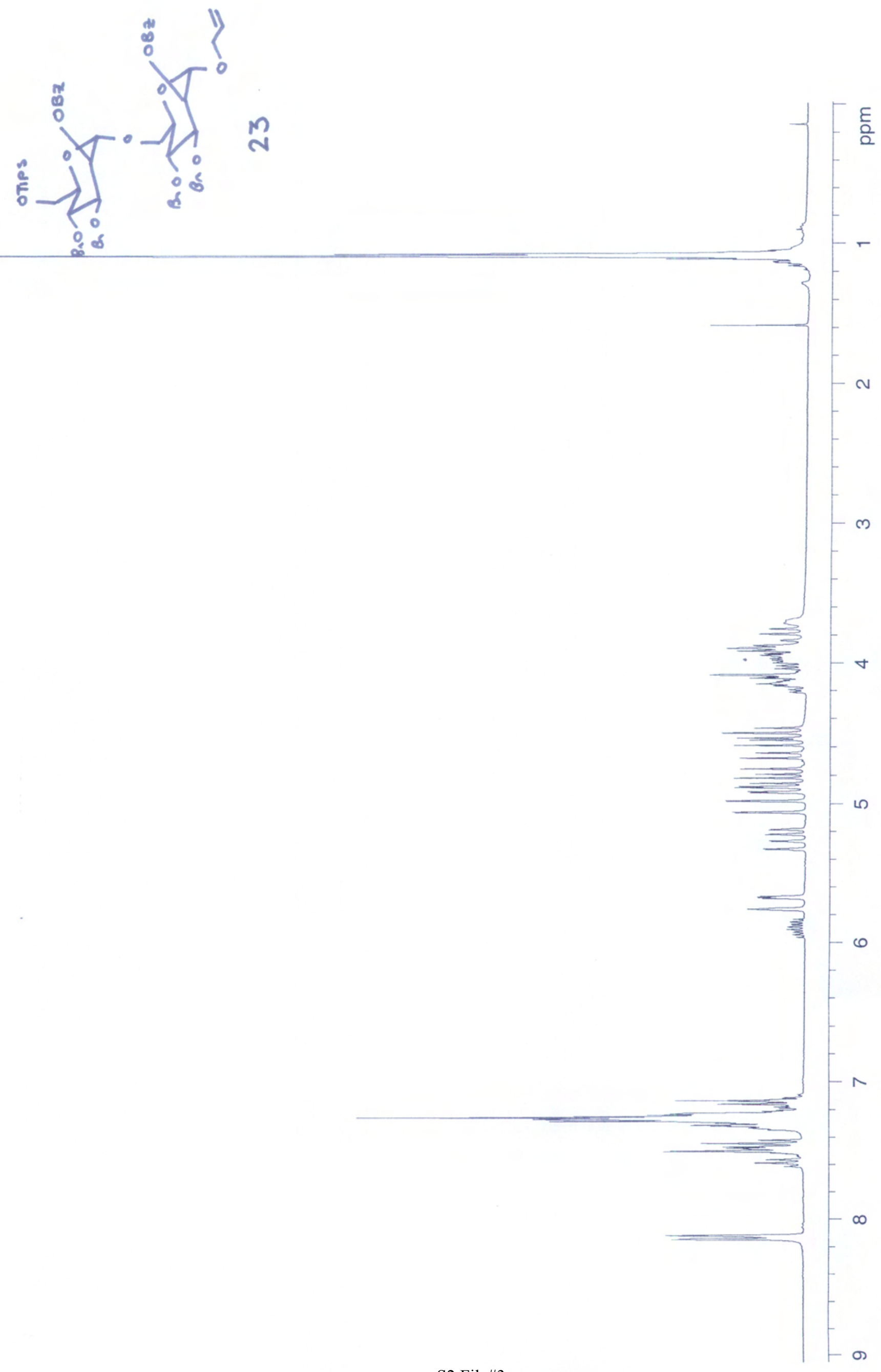

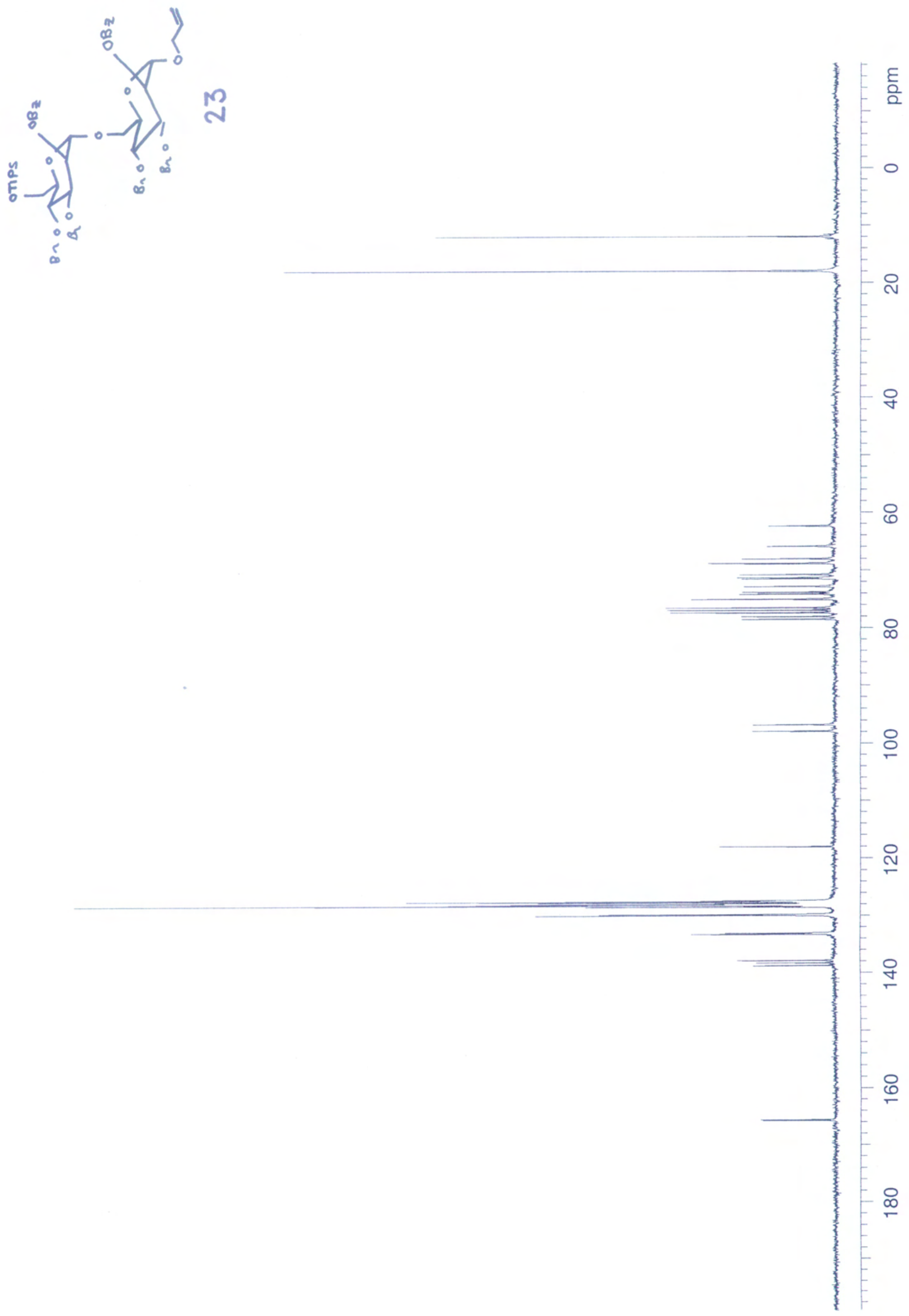

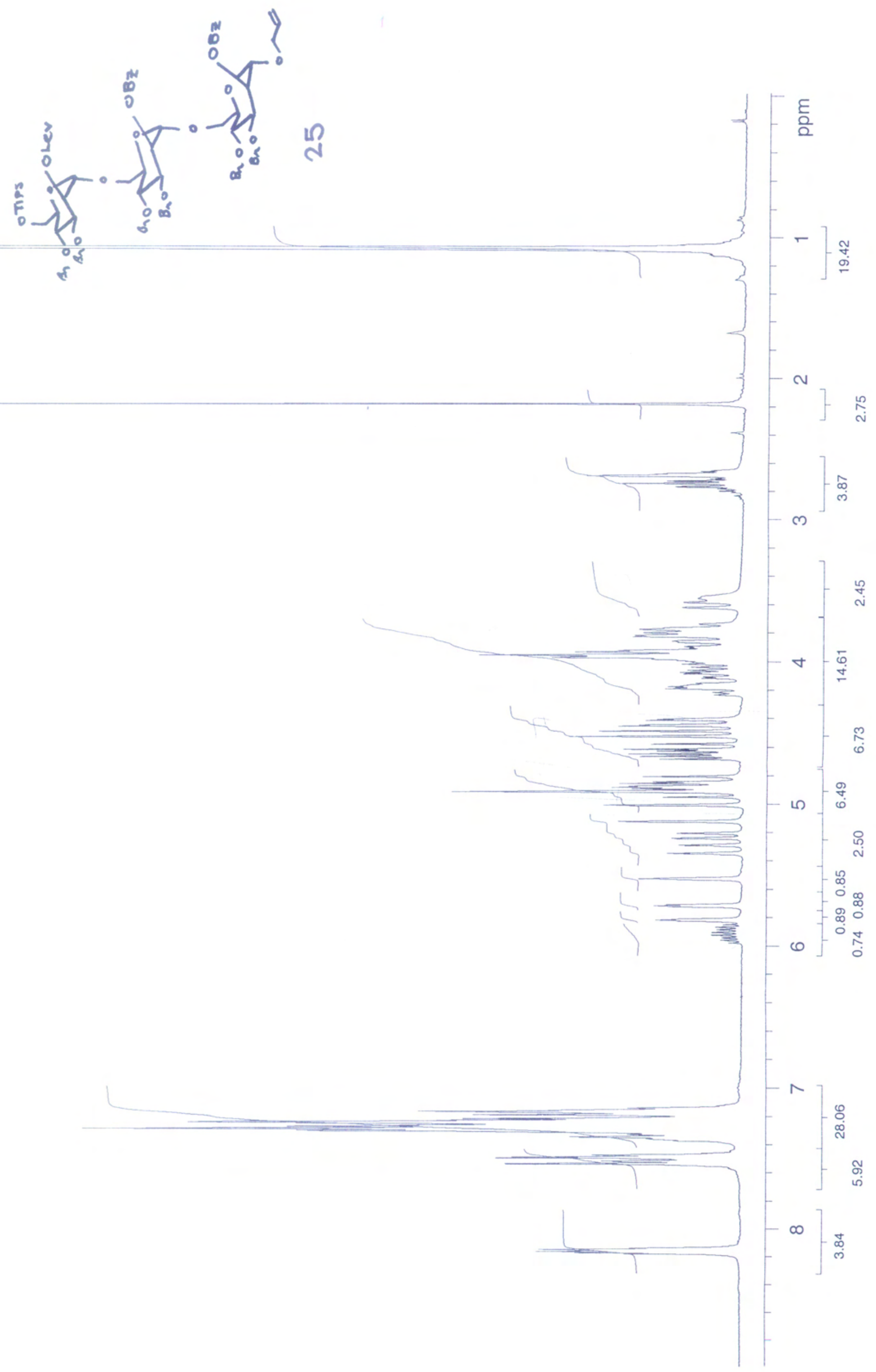

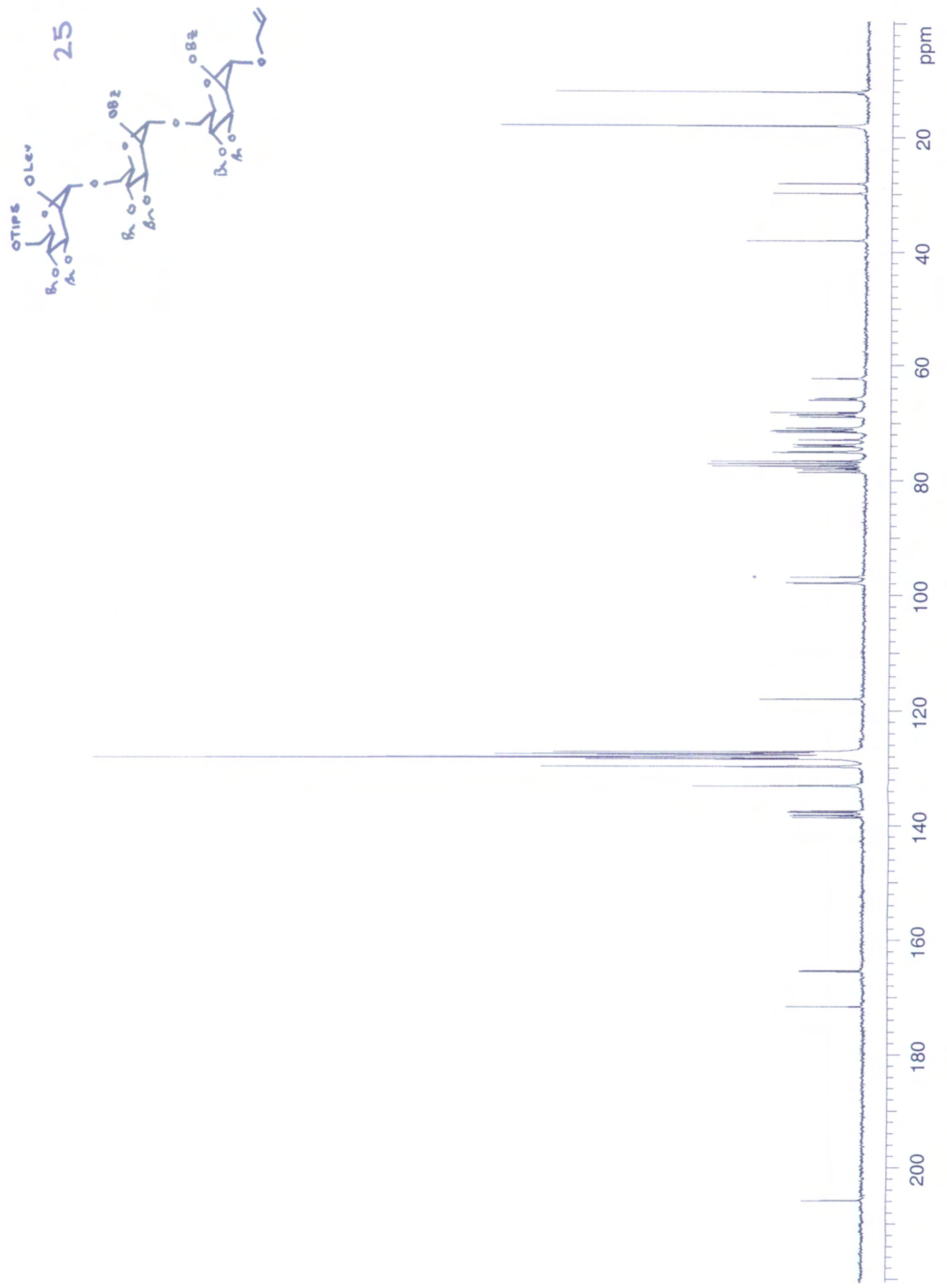


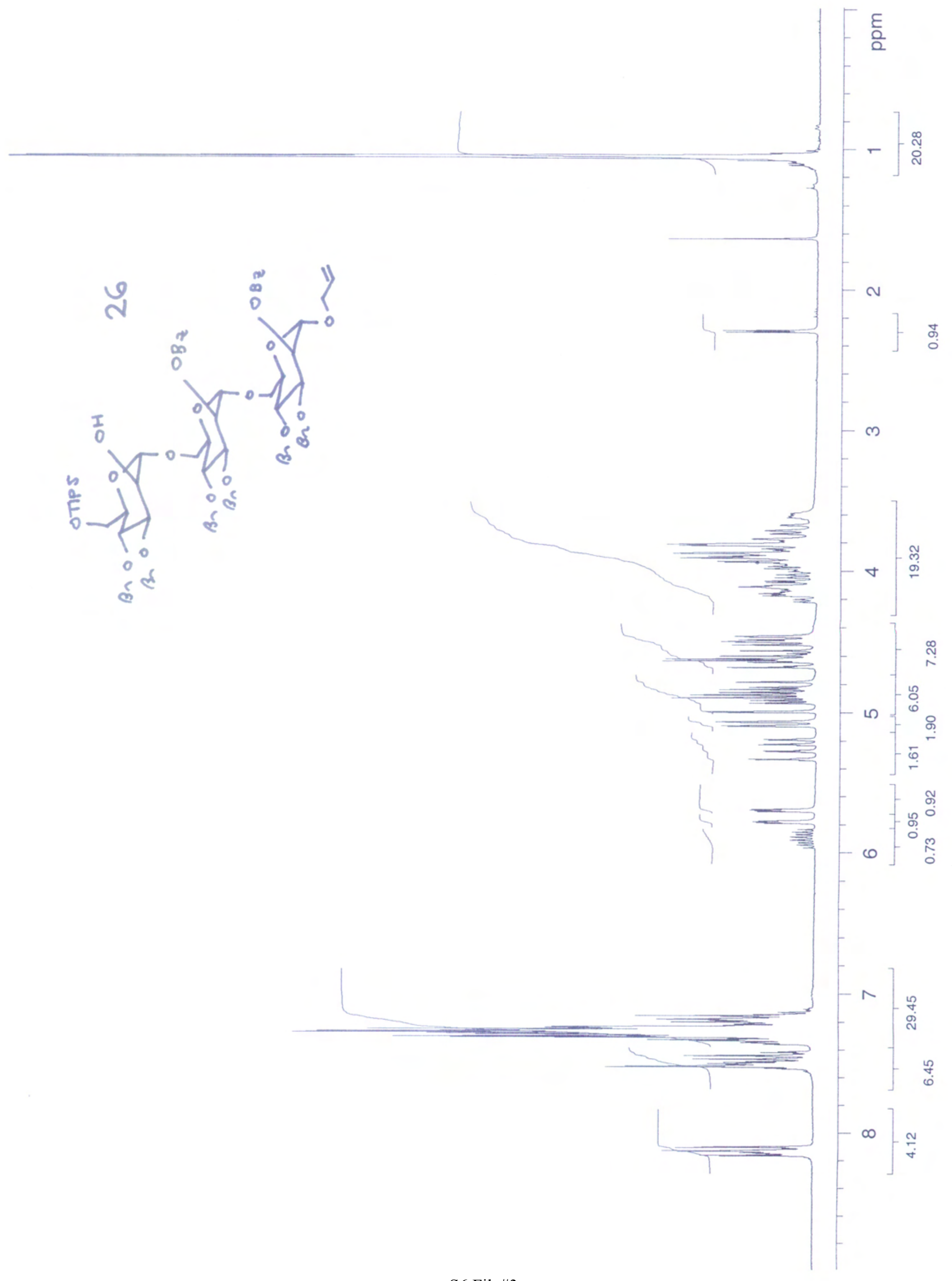




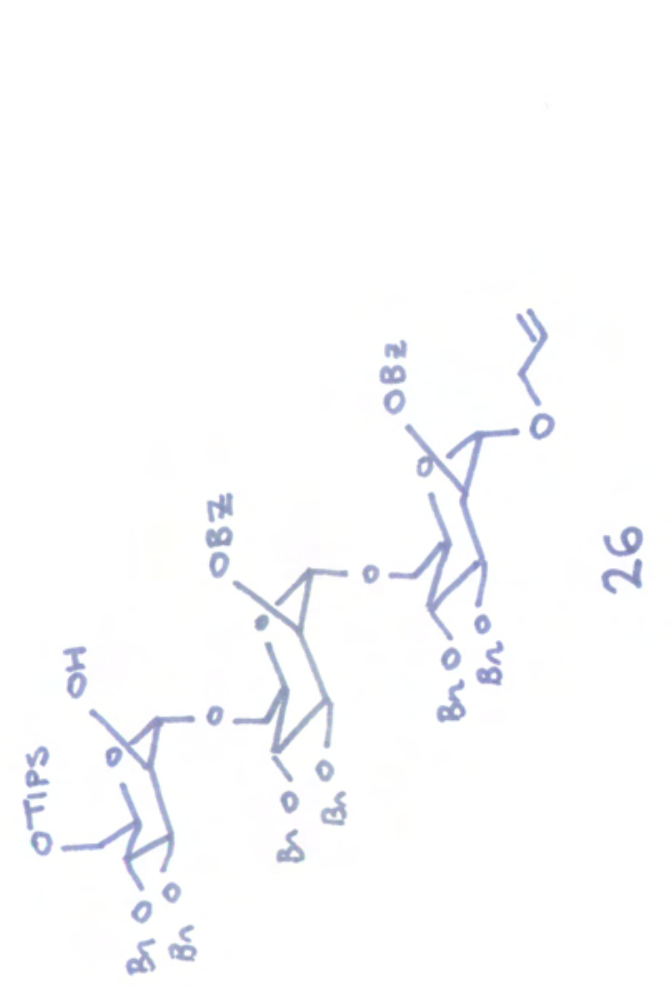




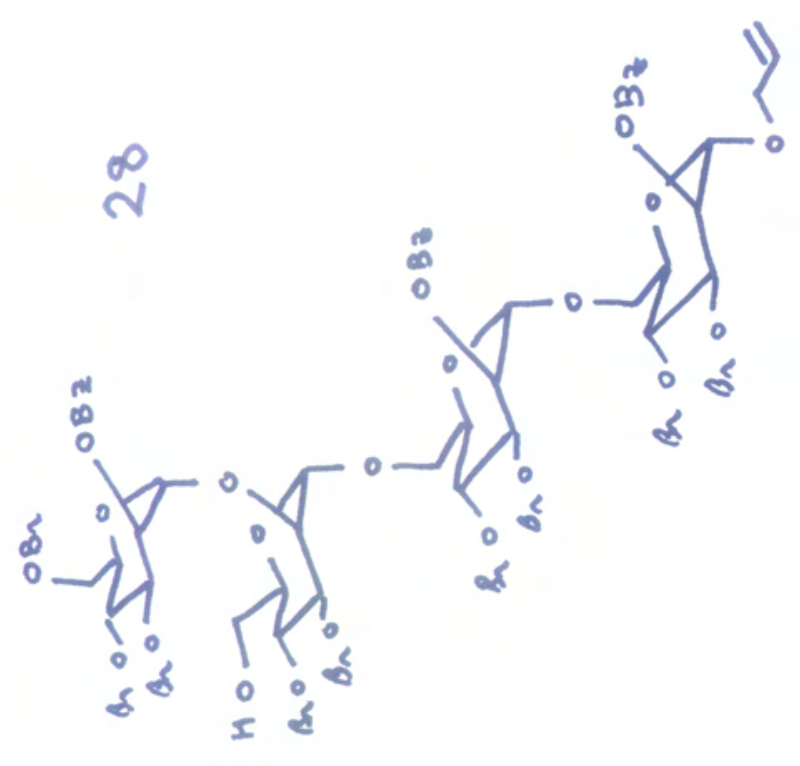

등

]

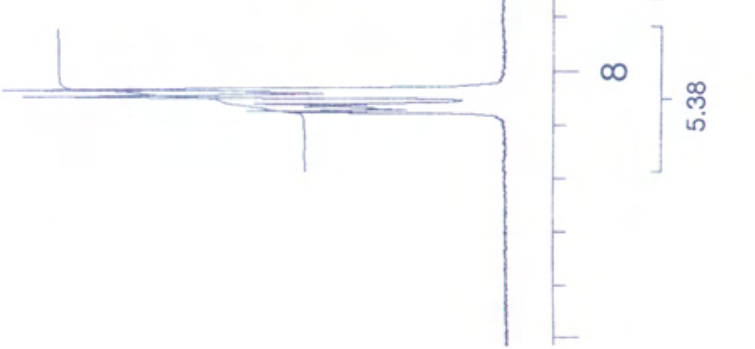




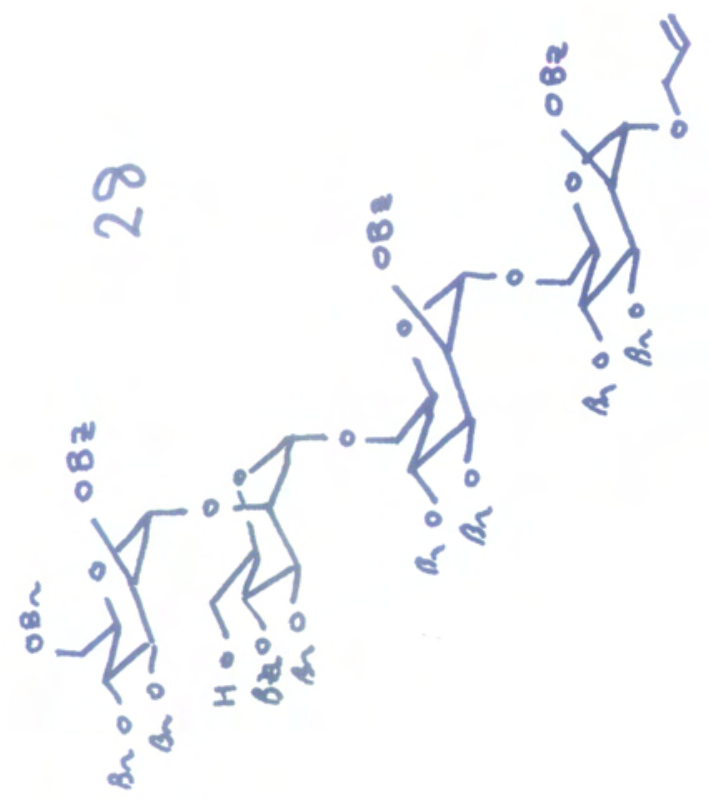




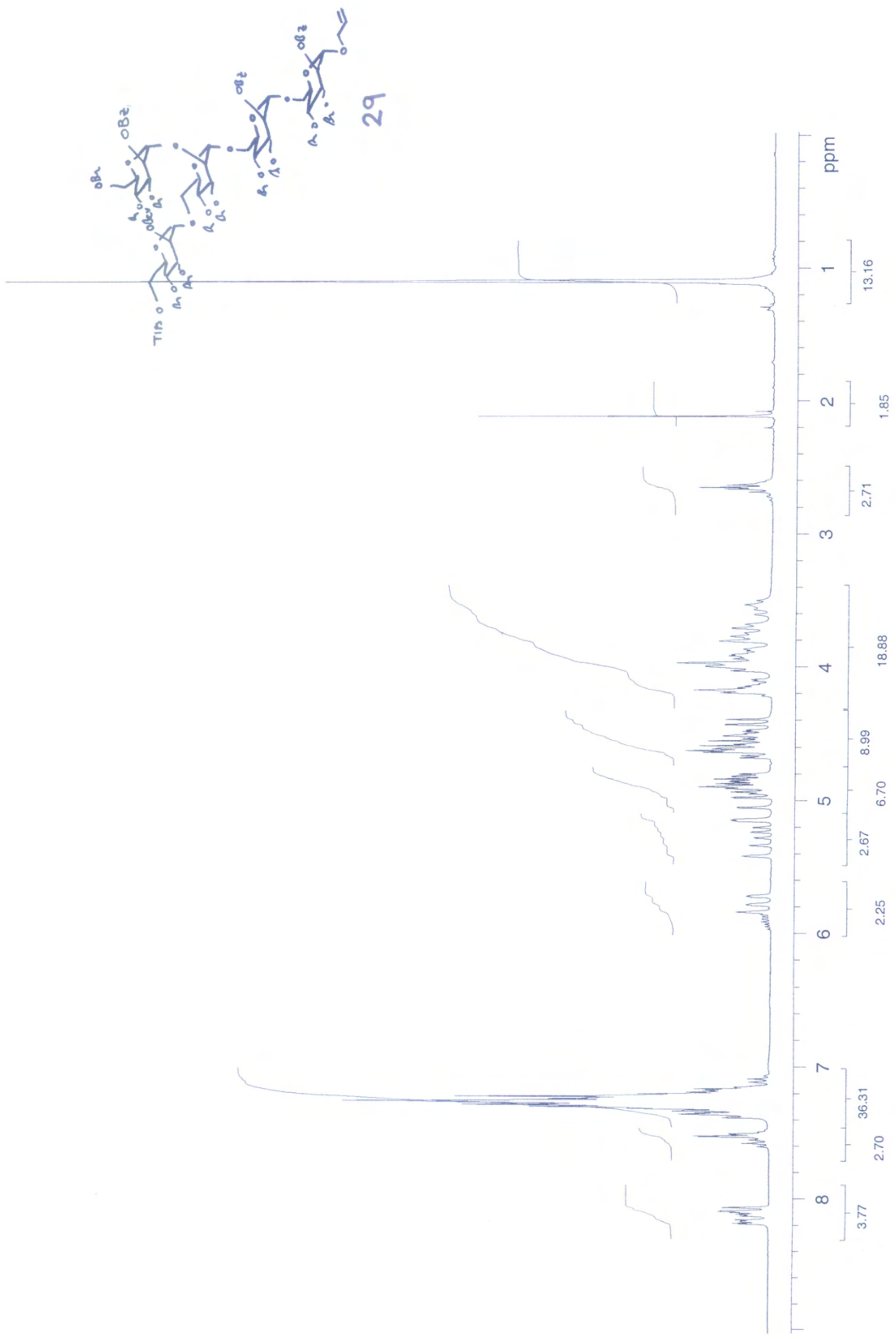

S10 File\#3 

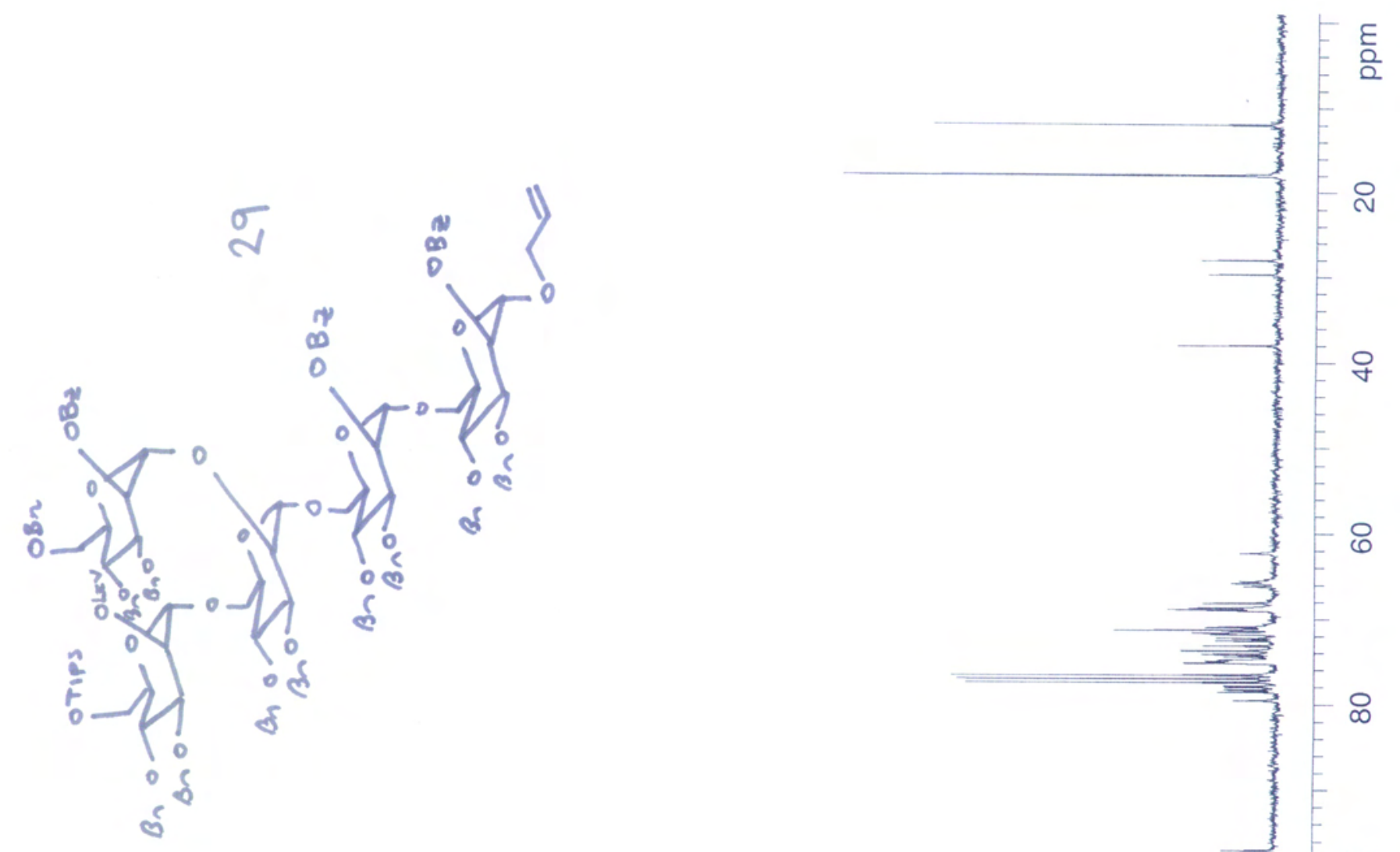

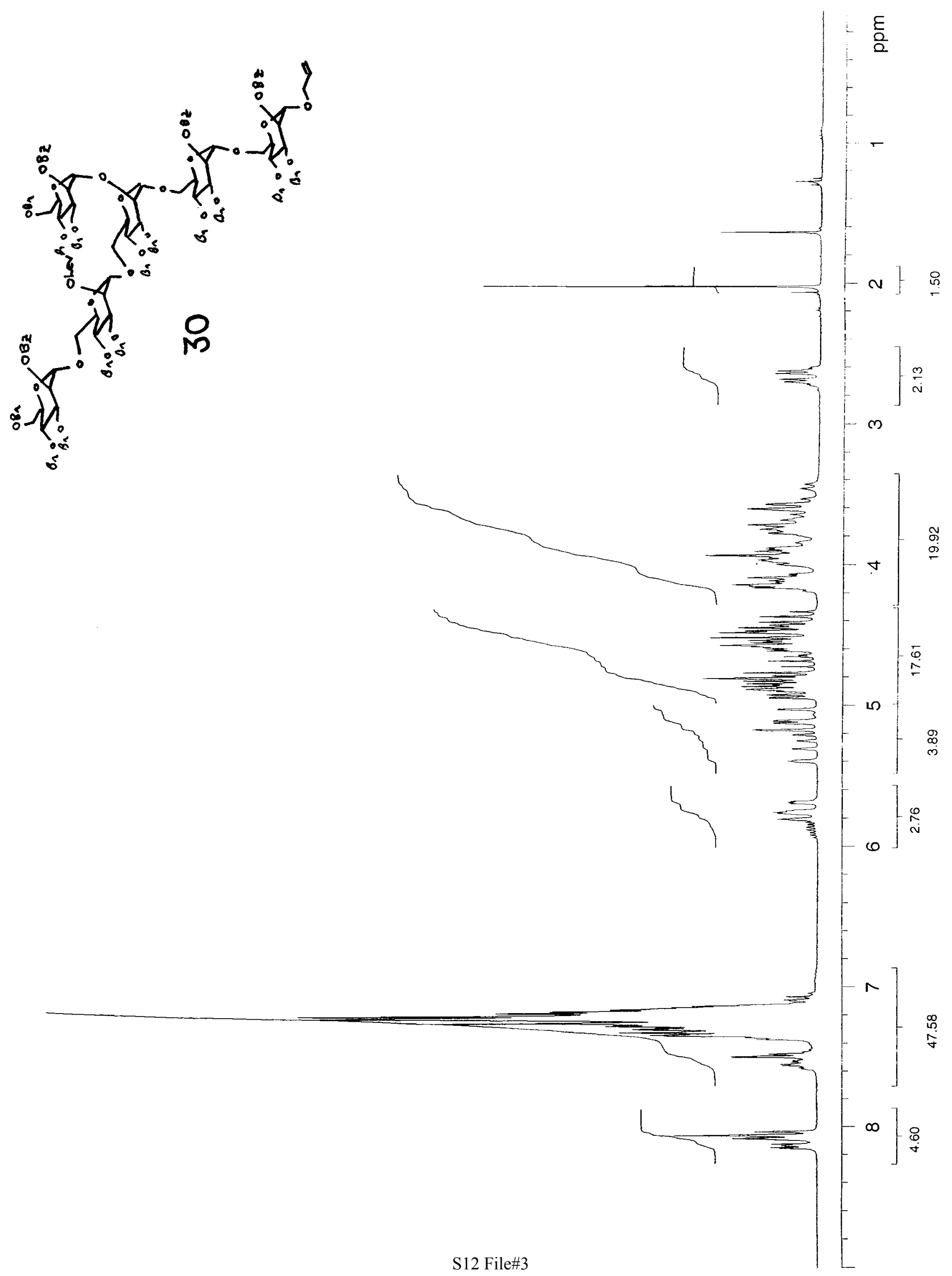

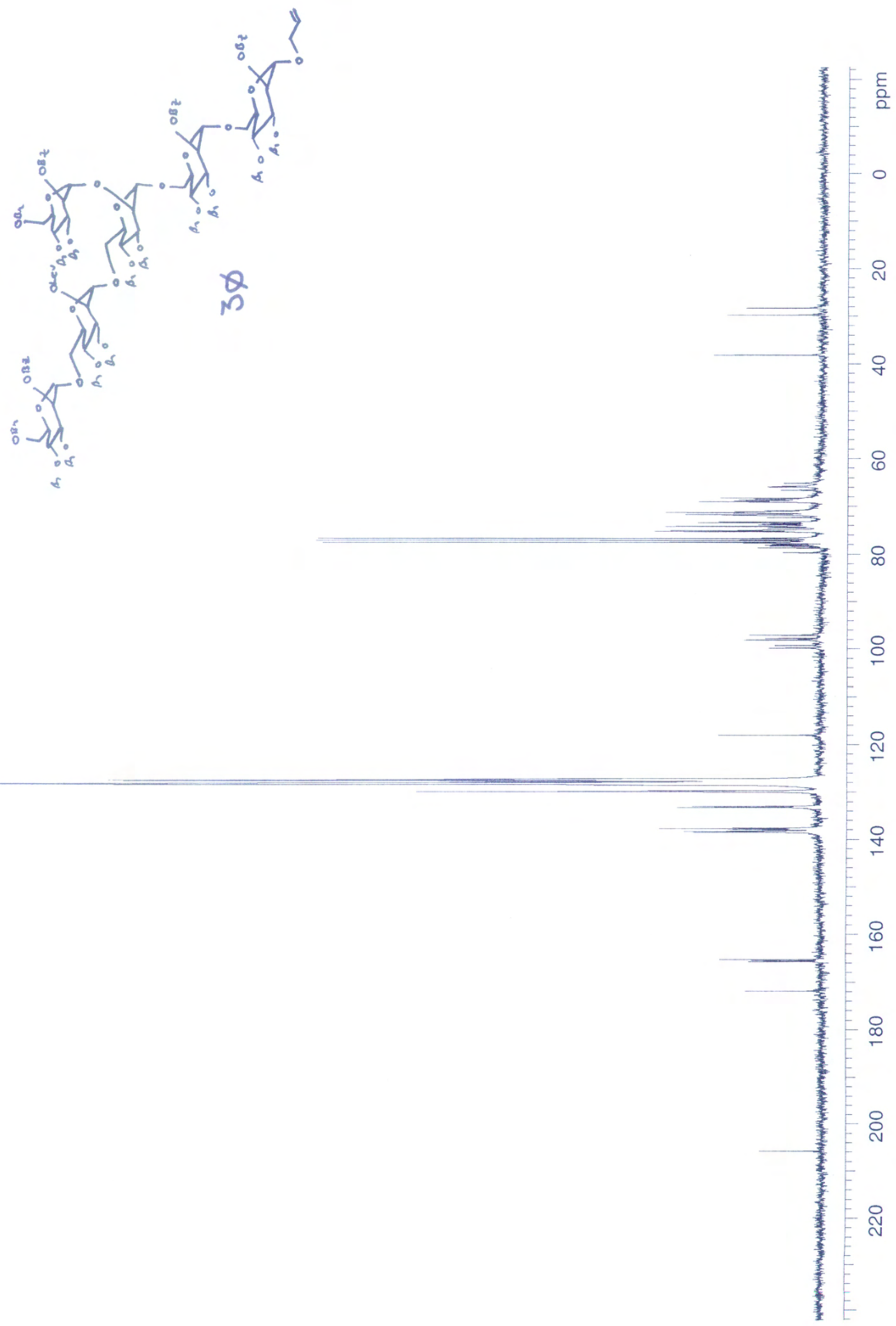


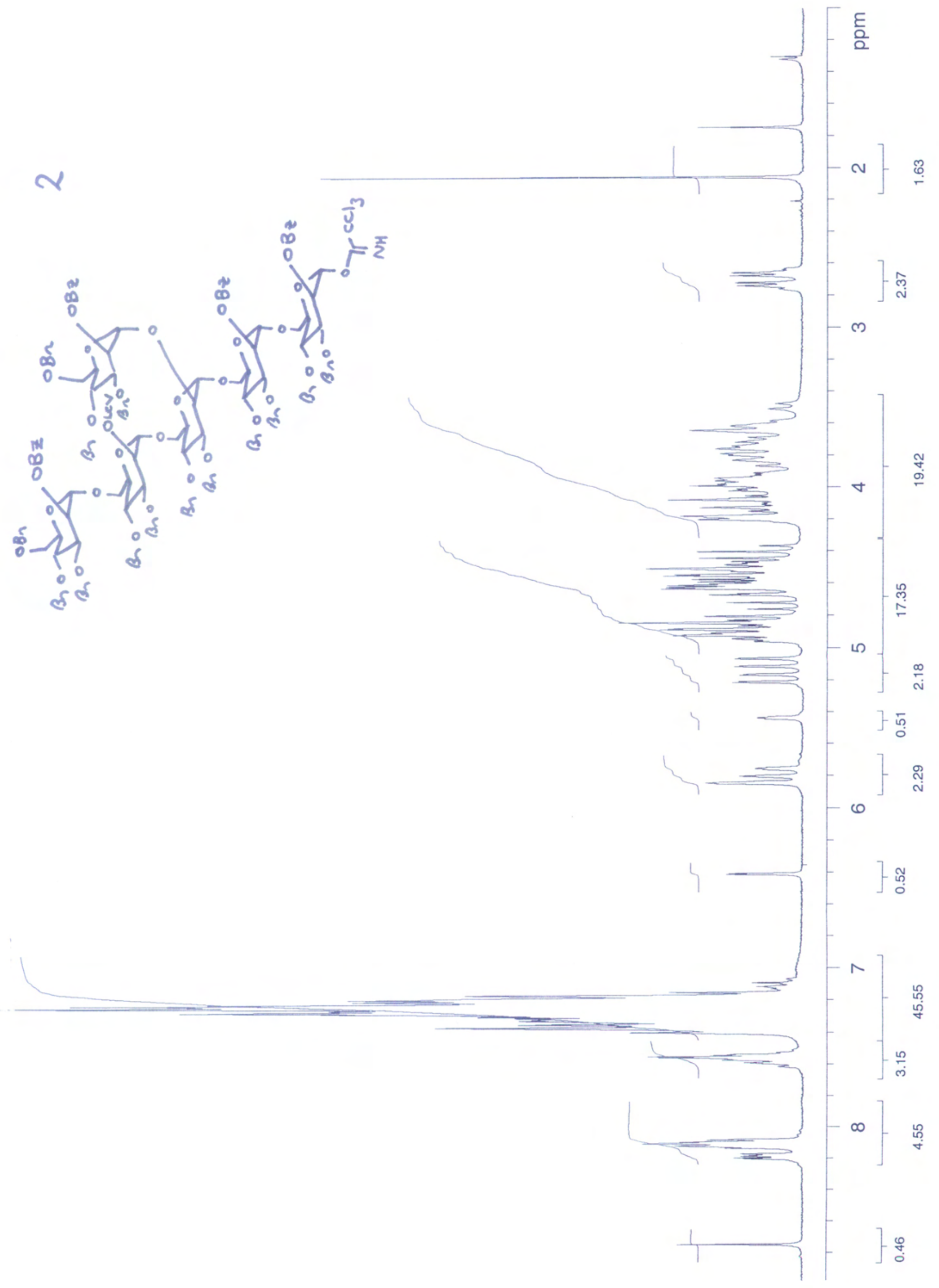




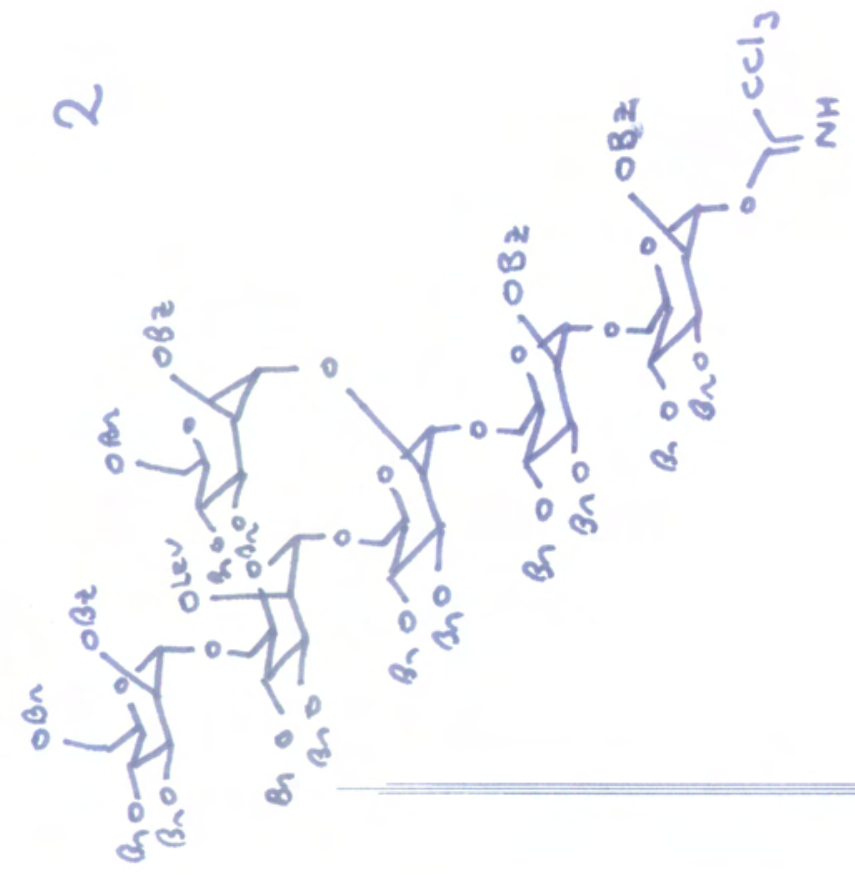




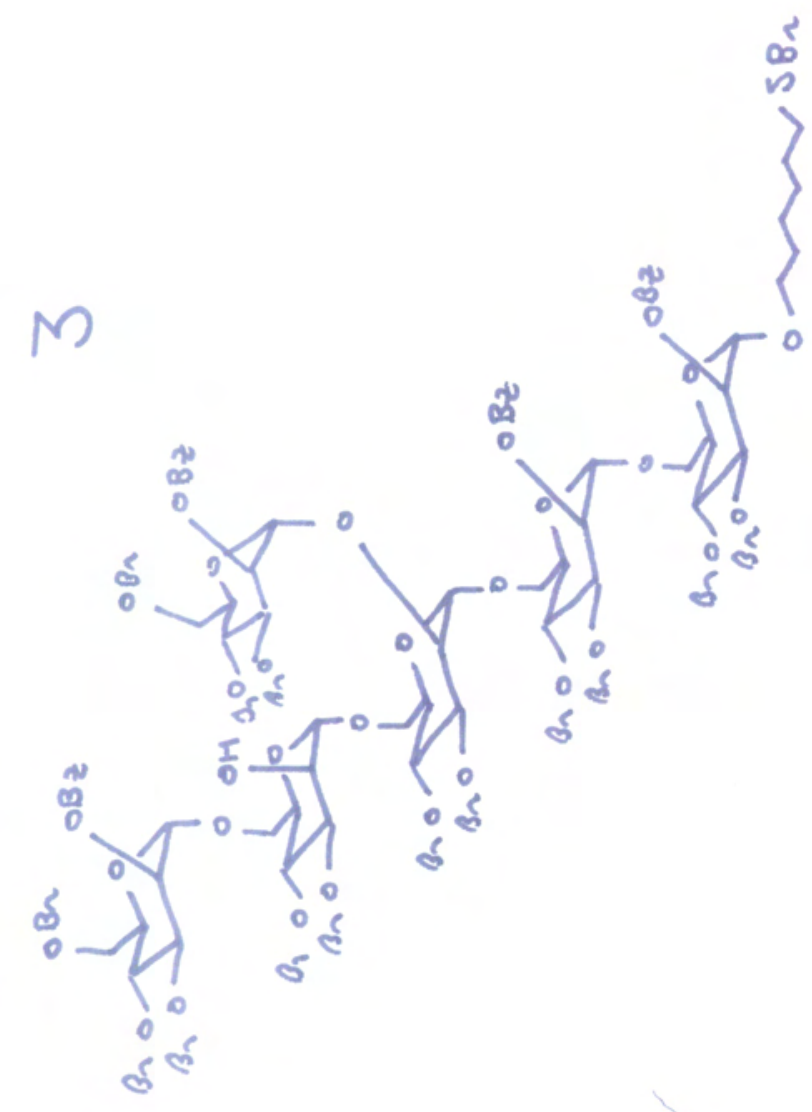

$\frac{\varepsilon}{2}$
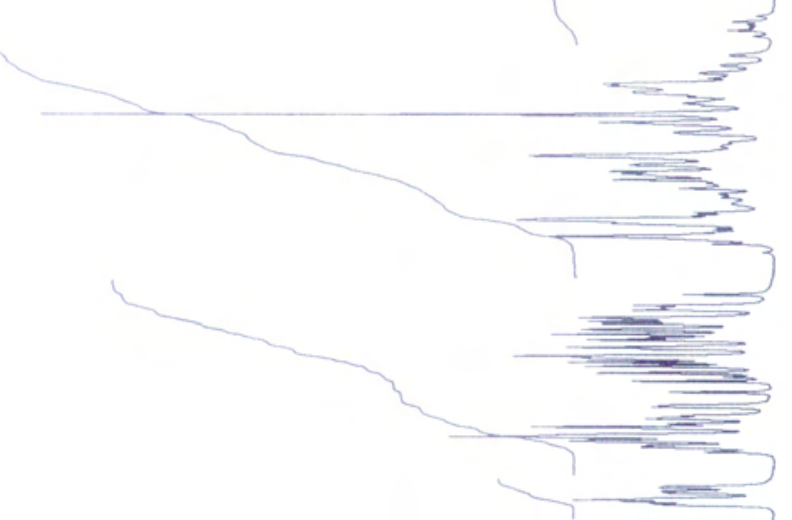

$-\infty$

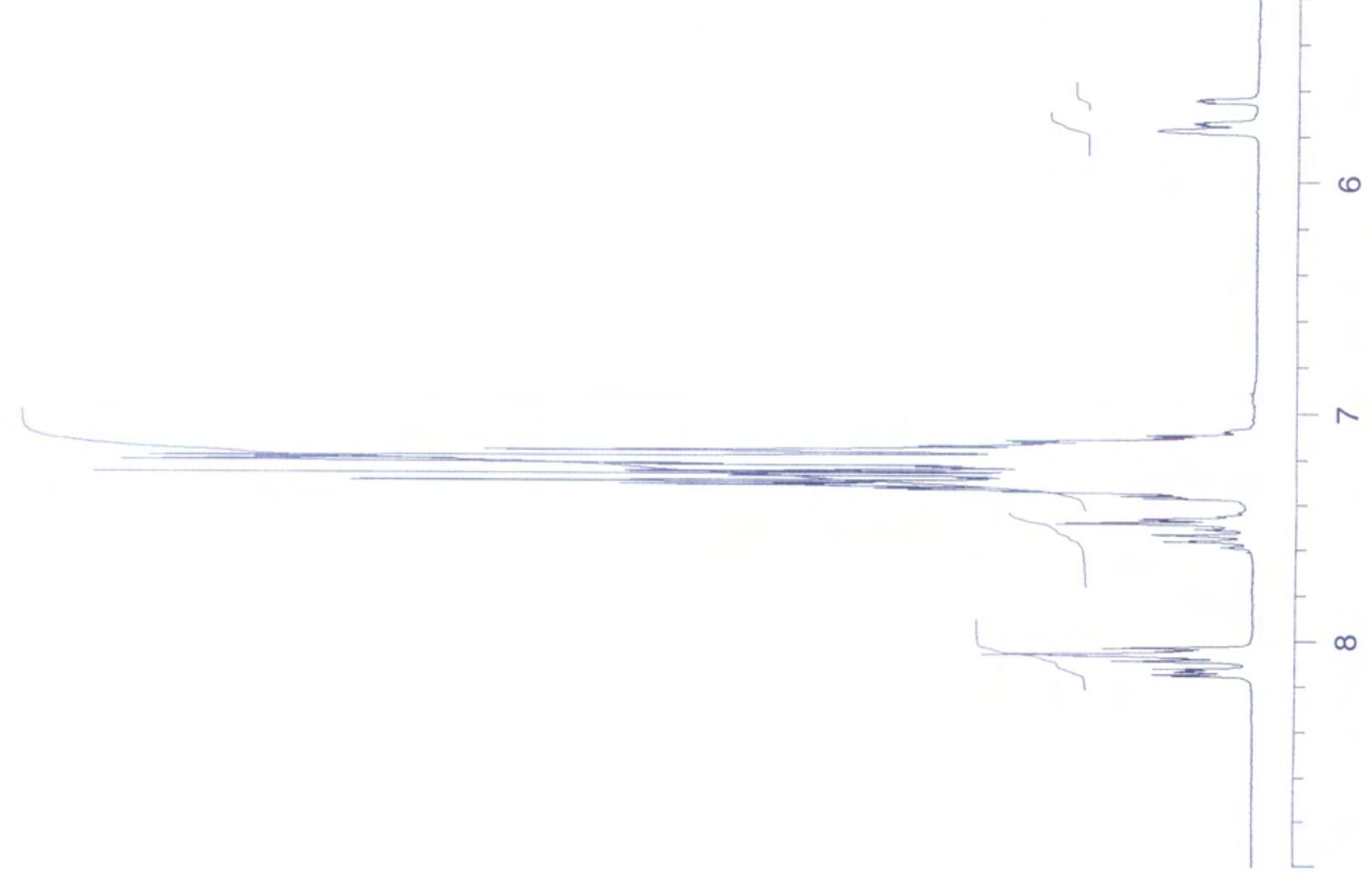


M

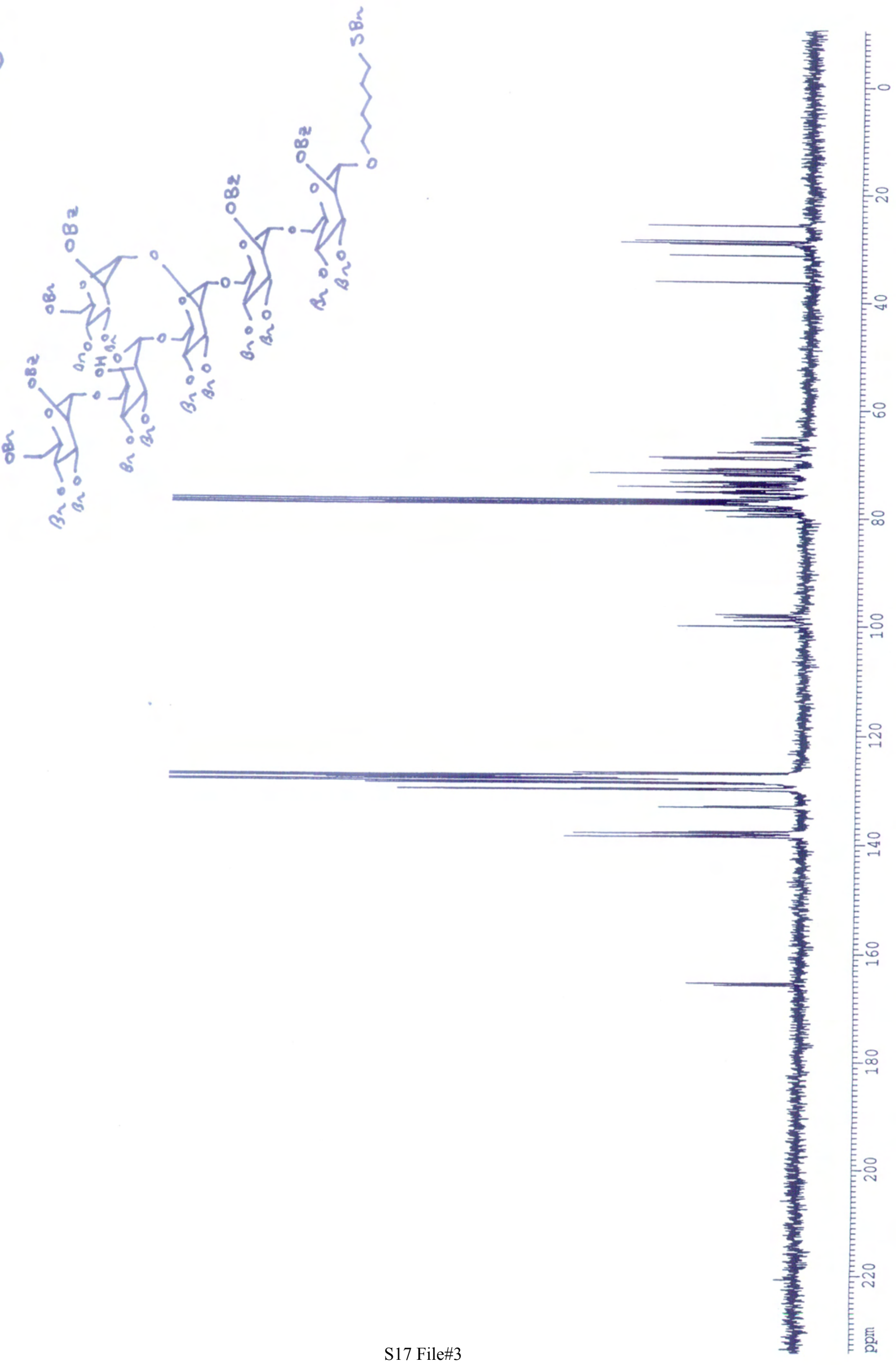




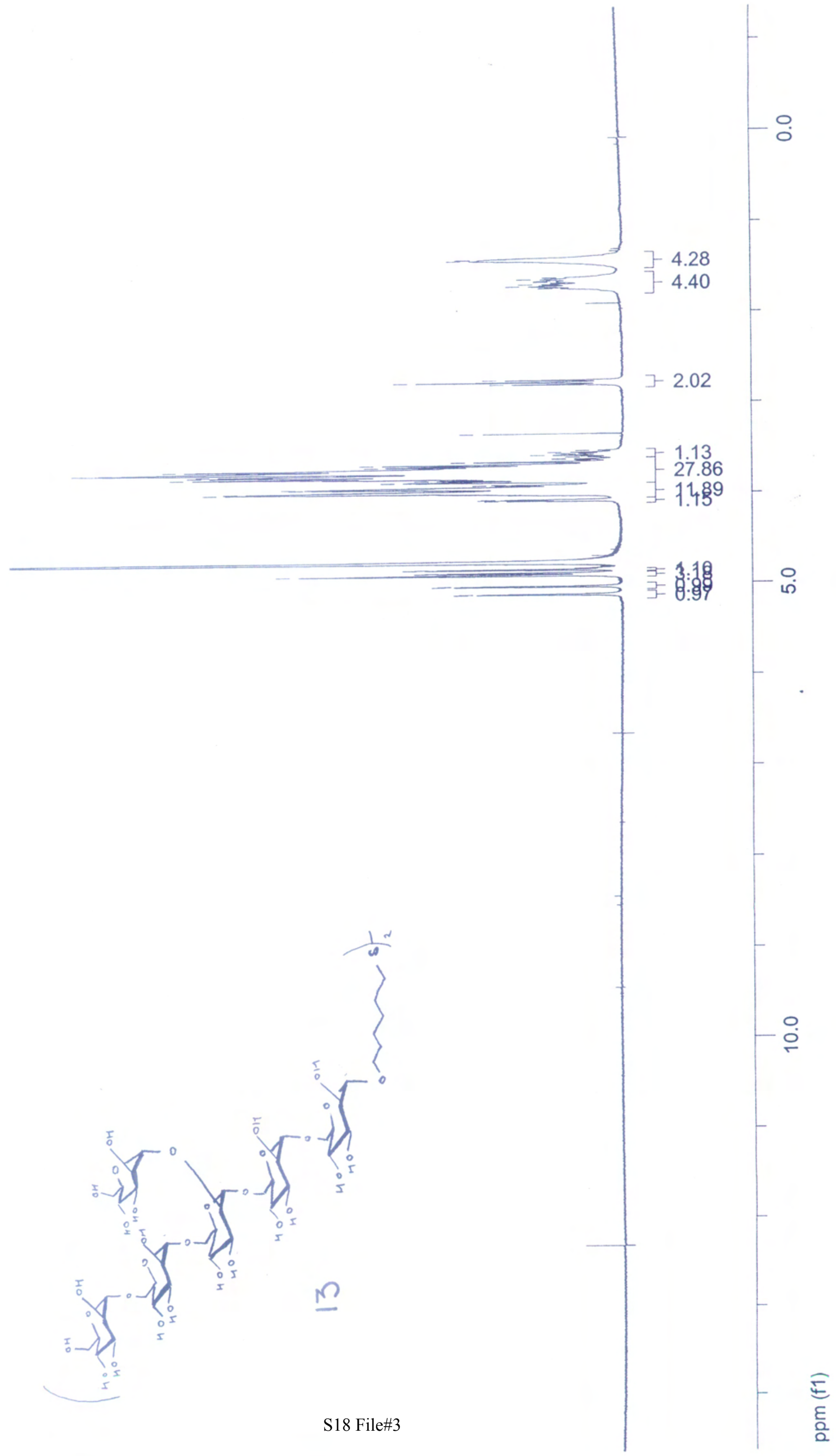


